\title{
The impact of research and technology organizations on firm competitiveness. Measurement and determinants
}

\author{
Andrés Barge-Gil · Aurelia Modrego
}

\begin{abstract}
The objective of this work is to evaluate the impact of research and technology organizations (RTO) on firm competitiveness. To this end, we develop a framework that includes strategies to deal with the methodological problems highlighted in the literature. The main features of this framework are the definition and classification of different types of impacts, the estimation of (rough) quantitative measures of them and the development of a multivariate model to explain the different impacts including the traditional indicators of firm characteristics and their relationships. The empirical work is based on a database constructed from information from the responses to a questionnaire designed specifically to estimate the impact of RTOs on Spanish firms, and information from the Spanish Inno vation Survey. Our findings show that firms are able to recognize the influence of these relationships on different technical, economic, investment and intangible impacts and to roughly estimate their economic impact, and that several characteristics of these rela tionships affect the impact of RTOs.
\end{abstract}

Keywords Impact evaluation · Collaboration · Innovation · Universities · Technology transfer

JEL Classification $\mathrm{O} 21 \cdot \mathrm{O} 25 \cdot \mathrm{O} 33$

\section{Introduction}

Firms' utilization of external sources of knowledge has grown impressively since the late 1980s (Arora et al. 2001; Hagedoorn 2002; Amara and Landry 2005), which has increased

\footnotetext{
A. Barge-Gil ( ()

Department of Foundations of Economic Analysis II (Quantitative Economics), Complutense University, 28223 Madrid, Spain

e-mail: abarge@ccee.ucm.es

A. Modrego

Laboratory for Analysis and Assessment of Technical Change, Carlos III University, C/ Madrid 126, 28902 Getafe, Madrid, Spain
} 
the interest of academics and policy makers in this area. More precisely, firms are increasingly turning to research and technology organizations (RTOs) to search for the knowledge required to be competitive. RTOs includes universities, public research centres and technology institutes (TI).

Most RTOs are public institutions, or, if private organizations, receive generous amounts of public funding. The evaluation of these organizations and of the links they establish with the productive sectors, however, is remarkably underdeveloped (Wren and Storey 2002; Perkmann and Walsh 2007), with many of the evaluations that have been carried being neither widely published nor circulated ('grey' literature') (Feller et al. 1996), making research into how they impact on different groups of firms a priority (Pietrobelli and Rabellotti 2007; Mole et al. 2008). The importance of our analysis is a reflection of the current trend towards a policy for more systematic analysis and evaluation of collaboration, and better design of programmes to satisfy needs (Mowery 1999), and to increased pressure generally for all public programmes to be evaluated (Roessner 2002).

The purpose of the present study is to evaluate the impact on the productive sector of the activities of Spanish RTOs. To this end, it delves into the problems associated with the measurement of impact, and proposes strategies to deal with them. We also develop a model to explain the impact in terms of firm characteristics, and relationships between RTOs and firms.

We believe this exercise, which summarizes the problems involved in evaluating the impact of technology transfer and collaboration, will be both interesting and valuable for academics and policy makers and will point to certain strategies that could be applied to address these problems. We show that certain strategies seem to be effective, and could be implemented in future research and policy. Our results allow us to distinguish different impacts of collaborative relationships and to get a better understanding of some of their determinants. This could be helpful for the design of policies to encourage interactions between RTOs and firms, and useful for the managers of both types of organizations involved in these relationships in showing that some practices are more effective than others. Our study and its results should be of great value to academics who, in recent years, have shown increasing interest in the interactions between science and industry. However, lack of appropriate data has restricted their studies mainly to an examination of the existence of linkages rather than the factors that render them more or less successful. ${ }^{1}$

The paper is organized as follows. In Sect. 2, we highlight the methodological problems commonly encountered in evaluating impact, and the strategies we adopt to address them. In Sect. 3, we describe the sample and in Sect. 4 we describe the measurement of the impact of RTOs. Section 5 defines the multivariate model used to explore the determinants of this impact and Sect. 6 provides some policy implications of our results. Section 7 concludes.

\section{Methodological problems and survey design}

Previous studies aimed at analysing the impact of relationships between agents or public initiatives, as well as evaluation studies more broadly, highlight several methodological problems, which can be summarized as follows:

- Problems related to data availability. Lack of specific, trustworthy and available sources of information that can be used to assess impact is one of the main barriers (Cozzarin 2008).

\footnotetext{
${ }^{1}$ An exception is the study by Brown et al. (1991) which covers a broader set of strategies.
} 
- The attribution problem deriving from the difficulties involved in isolating the effects of a specific relationship from those from the whole range of actions undertaken by a firm (Gallouj 1997; Williams and Rank 1998; Bozeman 2000).

- The different additionalities involved, defined as the difference rendered in the recipients by the action. Traditional studies consider only input and output addition ality. But some authors have claimed that 'behavioural' or 'strategic' additionality are more important and should be taken account of (Buisseret et al. 1995; Luukkonen 2000; Arnold 2004). In fact, there are great disparities in recommendations on how to acknowledge success (Geisler 2001). Impact is complex and multidimensional (Bozeman 2000; Lambrecht and Pirnay 2005) but many studies measure only some of its effects (Boekholt et al. 2001).

- A related problem is the estimation of the counterfactual situation (what would have happened had the relationship not been forged). This is very difficult to quantify.

- Quantification of the qualitative effects produced through the relationship. Firms find it difficult to quantify the impact of knowledge intensive services; for them, it is easier to identify the qualitative benefits (O'Farrell and Moffat 1995; Fromhold Eisebith and Schartinger 2002; van Helleputte and Reid 2004).

- The time lag between the relationship and the results, which are revealed only in the medium and long terms, especially the more intangible ones (Ham and Mowery 1998; Revilla et al. 2003). Also, there is no single moment in time when effects can be analysed and compared.

- Estimation of the main determinants of the impact, to enable better management of an initiative and improve future results. In a systems world, where many contextual factors influence the extent to which programmes achieve their objectives, these influences need to be evaluated (Arnold 2004).

The methodology in this study explicitly addresses each of these methodological issues using the following strategies.

- We designed a questionnaire for users, who are one of the richest sources for deriving an understanding of the impacts and processes in different initiatives. Surveying them provides many advantages (Shapira and Youtie 1998), although bearing in mind that responses risk being affected by some positive bias (Boekholt et al. 2001). We deal with lack of available data by administration of the survey.

- The attribution problem is more difficult to solve. We depart from the idea that estimations of attribution are more reliable from firms than from external agents. We deal with the problem in two stages. First, we asked firms about their relationships with their main partner (thus reducing the complexity of attribution); second, we asked firms explicitly how their companies would have evolved in the absence of this relationship. This strategy is novel in impact studies.

- The different additionalities involved, together with the complexity and variety of impact, have been tackled by distinguishing between different types of impacts: technical, economic and intangible, impacts on investment, and other types of impact. All are addressed in the questionnaire.

- Definition of a control group brings various complications (Youtie et al. 1999). Here, we chose to compare two groups of firms: firms whose main partner is a Public Research Organization (PRO) which includes both universities and public research centres, and firms whose main partner is a $\mathrm{TI}^{2}$

\footnotetext{
${ }^{2}$ That is, we compare two different treatments instead of one treatment versus non treatment.
} 
- The problem of impact quantification has been dealt with by simultaneous use of qualitative and quantitative effects for some types of impacts (technical, economic, and impact on inputs). It is important to combine both qualitative and quantitative methods in any evaluation and to test for consistency in the findings (Shapira et al. 1996; Boekholt et al. 2001).

- The time lag between actions and impacts in this study is 5 years in contrast to the 2 or 3 years period considered by most studies.

- The influence of different contexts and multifaceted influences on impact is managed by the definition of a holistic model to explain impact.

\section{The sample}

The sample is of firms, which, in the Official Innovation Survey administered by the Spanish Institute of Statistics in 2005, reported cooperation on innovation with TIs or PROs. ${ }^{3}$ The total number of firms was 2,357, of which 1,264 collaborated with TIs during 2003 2005, 1,529 with universities and 790 with PROs. Our specially designed survey was piloted and a number of questions were amended or dropped as a result of the pilot phase.

Each firm was required to answer questions related to the TI or PRO that was considered to be its main partner. Our survey asked for the names of partners, a strategy that allowed us to make a manual reclassification of the type of organization. ${ }^{4}$ We obtained 309 answers, although our final sample is composed of 257 firms, 134 of which cooperate with a TI and 123 with a PRO. Another 52 responses identified some other organizations as main partners. This mix included public bodies (such as several national departments, and the EU), some identified funding agencies and regional development agencies, some identified consultancy firms and private partners along the value chain. The impossibility of developing coherent and statistically relevant classifications for these organizations led us to excluding them from our analysis.

As response bias is a significant problem in surveys of users (Youtie et al. 1999), we analysed the differences between respondents and non respondents based on such variables as: total sales, total exports, location, sectoral distribution and various indicators of innovative behaviour (innovation intensity, weight of internal research and development (R\&D) intensity, distribution of R\&D expenses and composition of R\&D personnel). We found no significant differences at a $p$ value of 0.1 .

\section{Impact of RTOs}

\subsection{Differences between TIs and PROs}

We have stated that instead of a control group we compare the impacts of two different types of organizations: PROs and TIs.

PROs, which include universities and public research centres, are mainly focused on research. TI are private, non profit organizations that perform a wide range of knowledge

\footnotetext{
3 This was the latest wave available at the start of this study.

4 Around $20 \%$ of firms wrongly categorized their partners. Some university institutes or PROs were categorized as TIs and, conversely, some TIs were put into the PRO category.
} 
based activities oriented to enhancing firm competitiveness. Most were created through the joint efforts of private and public agents (mainly regional), which are represented on their boards of directors. They are key organizations in the Spanish National Innovation System (NIS) based on their size and closeness to the productive sector (Modrego Rico et al. 2005). There are 82 TIs in Spain, but their regional distribution is rather unequal.

Before embarking on the analysis we need to identify some of the differences between the two types of organization we are studying. ${ }^{5}$ First, there are differences in terms of objectives. TIs are oriented specifically towards enhancing the competitiveness of Spanish firms by improving their innovation performance while PROs have a much wider remit. They are mandated to undertake basic and applied research to advance the knowledge frontier and, in the case of universities, to train students, which is a core mission. In addition, universities are now required to take on a so called 'third mission, which involves directly contributing to innovation in the productive sector several channels, being the most common through joint research projects and the provision of innovation services (D'Este and Patel 2007). It is the impact of this third mission which we think is the most comparable with the impact of TIs. ${ }^{6}$ Second, TIs provide firms with a wide range of knowledge intensive services, while PROs mainly offer assistance for R\&D projects, and access to equipment. Third, PROs employees mainly have scientific profiles while TI staff are more oriented to technology experts and people with management capabilities. This allows them to offer 'technoeconomic capabilities'. Fourth, TIs are usually more immersed in the regional economy, and their councils tend to include stakeholders from the local public and private sectors; although PROs are striving to become better embedded in their local context, there are some cultural and cognitive barriers that make interaction with private local agents difficult. Fifth, TIs operate under more flexible management compared to the bureaucracy common to PROs.

\subsection{An overview of the impacts considered}

As already mentioned, one of the main issues involved in studying impact is its complexity and multidimensionality. In this study we propose an impacts classification to try to tackle this variety ${ }^{7}$ (a copy of the questionnaire is provided in Appendix 1).

Technical impact: this refers to the specific, direct and more immediate results of each project in terms of technical outputs: new or improved goods; new or improved services; new or improved production methods; improvements in logistics and patents.

Economic impact: this is the short and medium term (more or less) direct effects of the relationship on economic aspects of the firm: sales; exports; production costs; profits (before tax); productivity; employment; and number of clients.

Impact on inputs: this is related to changes in the investment behaviour of firms (the so called 'input additionality'). It reflects how current changes may indirectly affect future performance. The investments considered are: facilities and machinery; information and

\footnotetext{
5 For a more in depth analysis of these differences, see Barge-Gil et al. (2008).

6 It is crucial to point out that the overall impact of PROs in productive sector competitiveness is much higher, as there are many indirect impacts stemming from training and academics' own research. In other words, our analysis should not be seen as an evaluation of universities' performance overall, but only of their more usual third mission activities. However, in the case of TIs our analysis can be regarded as an evaluation of these organizations as a whole since their activities are oriented entirely towards improving competitiveness through joint research and the provision of innovation services.

7 These impact categories are highly interrelated, especially over time. An examination of these interrelations, however, is beyond the scope of this study, but it is an interesting topic for future research.
} 
software systems; new methods of human resource management and training; internal $\mathrm{R} \& \mathrm{D}$; external R\&D; acquisition of technology, patents and licenses; and external, non $\mathrm{R} \& \mathrm{D}$ related innovation services.

Intangible impact: this is the effect of the relationship on the firm's intangible assets which may affect its long term competitiveness. We consider the categories of: learning and staff training in new areas; enhanced ability for teamworking and knowledge sharing; better market understanding; enhanced ability to define and plan innovation activities; better use and selection of information and software systems; improved relationships between R\&D and other departments in the firm; improved utilization of external knowledge sources; and better information on public innovation programmes.

Other impacts: in this category we include some qualitative measures of impact from the literature: a general measure for customer satisfaction; and the additionality offered by the RTO in terms of speed, ambitiousness and efficiency of projects.

In what follows we describe the impacts of TIs and PROs in each of these categories.

\subsection{Technical impact}

Technical impact is very similar for TIs and PROs (Table 1). The main impact of both organizations is the achievement of new or improved goods $(57.6 \%$ of TIs' clients and $60.7 \%$ of PROs' clients), with logistics and patents being less frequent technical outputs (in both cases slightly above $10 \%$ ). Although the percentage of firms reporting that they had obtained technical results is slightly higher among firms interacting with PROs, the dif ference is not statistically significant. The most obvious difference is related to achieve ment of new or improved services (47.3\% for PROs' clients and $38.4 \%$ for TIs' clients).

\subsection{Economic impacts}

\subsubsection{A qualitative approach}

We started with a qualitative approach to economic impacts, asking firms whether certain economic indicators were very positively affected, positively affected, not affected, neg atively affected or very negatively affected by their relationships with a TI or PRO partner. In what follows, we distinguish between a positive and a null or negative impact (the latter being very unusual).

The economic impacts of relations with TIs and PROs are very similar (Table 1). The type of impact most frequently declared by firms is impact on sales, followed by profits, number of clients and productivity.

The impact of TIs is slightly higher for exports (26.4 vs. $24.1 \%$ of clients) and profits (48.4 vs. $46 \%$ of clients), while PROs' impact was higher for sales $(65.1$ vs. $56.6 \%$ of clients), production costs (36.3 vs. $29.6 \%$ ), productivity (42.5 vs. $37.3 \%$ ), employment (33.6 vs. $27 \%$ ) and number of customers (43.4 vs. $38.4 \%$ ). However, from a statistical point of view these differences are not significant.

\subsubsection{A quantitative approach}

We also wanted a quantitative approach to impact. Because we were concerned about the difficulty for firms to estimate this, we adopted the strategy described below to obtain a rough estimate of this impact. 
Table 1 Impacts of TIs and PROs

\begin{tabular}{|c|c|c|c|c|}
\hline & \multicolumn{2}{|c|}{$\begin{array}{l}\% \text { Of firms } \\
\text { declaring a } \\
\text { positive impact }\end{array}$} & \multicolumn{2}{|c|}{$\begin{array}{l}\% \text { Of contribution } \\
\text { reported to each } \\
\text { impact (mean) }\end{array}$} \\
\hline & TIs & PROs & TIs & PROs \\
\hline \multicolumn{5}{|l|}{ Technical impacts } \\
\hline New or improved goods & 57.6 & 60.7 & & \\
\hline New or improved services & 38.4 & 47.3 & & \\
\hline New or improved production methods & 38.1 & 44.6 & & \\
\hline Improvements in logistics & 10.4 & 11.6 & & \\
\hline Patents & 11.3 & 12.8 & & \\
\hline \multicolumn{5}{|l|}{ Economic impacts } \\
\hline Sales & 56.6 & 65.1 & 27.3 & 27.5 \\
\hline Exports & 26.4 & 24.1 & 11.5 & 11 \\
\hline Production costs & 29.6 & 36.3 & 14.2 & 11.3 \\
\hline Profits (before taxes) & 48.4 & 46 & 28.4 & 21.9 \\
\hline Productivity & 37.3 & 42.5 & 18.3 & 19.2 \\
\hline Employment & 27 & 33.6 & 17.7 & 15.3 \\
\hline Number of clients & 38.4 & 43.4 & 21.8 & 21.4 \\
\hline \multicolumn{5}{|l|}{ Impact on investment } \\
\hline Facilities and machinery & 36.8 & 42.2 & 17.1 & 15.8 \\
\hline Information and software systems & 28 & $42.2 *$ & 12.6 & $20.6^{*}$ \\
\hline New methods of human resource management and training & 13.7 & 14.7 & 6.3 & 4.6 \\
\hline Internal R\&D & 60.2 & 68.8 & 32.5 & 38.5 \\
\hline External R\&D & 56.8 & 56.5 & 37.7 & 34.3 \\
\hline Acquisition of technology. Patents and licenses & 26.4 & $37.6^{* *}$ & 16.9 & $22.6^{*}$ \\
\hline External. non-R\&D related innovation services & 31.5 & 23.9 & $21.9 * * *$ & 9.1 \\
\hline \multicolumn{5}{|l|}{ Intangible impact } \\
\hline Learning and staff training on new areas & 71.6 & 77.1 & & \\
\hline Enhanced ability to teamwork and knowledge sharing & 59.4 & 65.1 & & \\
\hline Better market understanding & 39.8 & 22.1 & & \\
\hline Enhanced ability to define and plan innovation activities & 64.3 & 56.9 & & \\
\hline Better use or selection of information and software systems & 28.5 & 35.2 & & \\
\hline $\begin{array}{l}\text { Improved relationship between firm's R\&D and other } \\
\text { departments }\end{array}$ & 22.8 & $43.1 * * *$ & & \\
\hline Improved utilization of other knowledge external sources & 78 & $87.2^{* *}$ & & \\
\hline Better information on public innovation programs & $77.3 * *$ & 63.3 & & \\
\hline
\end{tabular}

$* * * p$-value $<0.01, * * p$-value $<0.05, * p$-value $<0.1$

Firms were asked to report mean yearly rate of growth in several economic indicators, over the previous 5 years (I1), and the estimated mean yearly rate of growth had the relationship with their main TI or PRO partner not taken place (I2). Based on this infor mation we made an estimation of the percentage of growth in each indicator that could be attributed to the relationship with the firm's main partner (I3). If the information provided by the responses to this question contradicted that derived from the question before (the qualitative approach), we contacted the firm to explain this disagreement and contradiction 
and elicit their reasons. Misunderstanding of what was being asked was the main reason for discrepancy. After some explanation, we were able to obtain a more coherent estimation.

Next, we used the following robust procedure $^{8}$ to obtain the final indicator (I3):

1. If $\mathrm{I} 1>0$ and $\mathrm{I} 2>0$, then $\mathrm{I} 3 \quad[(\mathrm{I} 1 \quad \mathrm{I} 2) / \mathrm{I} 1] \times 100$

2. If $\mathrm{I} 1<0$, then $\mathrm{I} 3 \quad[(\mathrm{I} 2 \mathrm{I} 1) / \mathrm{I} 1] \times 100$

3. If I1 I2 0 , then I3 0

4. If I1 0 and $\mathrm{I} 2>0$, then $\mathrm{I} 3 \quad 100 \%$

5. If I1 0 and $\mathrm{I} 2<0$, then $\mathrm{I} 3 \quad 100 \%$

6. All I3 outside the interval [ 100\%, 100\%] are substituted by the closest extreme

We accept, of course, that this is a rough quantitative estimate, but it shows that the impact of TIs is slightly higher to that of PROs (Table 1). Differences are sharper for production costs, exports and number of customers. However, none of the differences are statistically significant.

\subsection{Impact on investments}

\subsubsection{A qualitative approach}

The type of investment more frequently affected by relationships with TIs or PROs is internal $\mathrm{R} \& \mathrm{D}$, followed by external $\mathrm{R} \& \mathrm{D}$, facilities and machinery, and information and software systems (Table 1).

Again, impacts are quite similar. While TIs have a bigger influence on external R\&D investments (56.8 vs. $56.5 \%$ of clients) and on other non R\&D related innovation services (31.5 vs. $23.9 \%$ of clients), PROs have a bigger impact on investments related to facilities and machinery (42.2 vs. $36.8 \%)$, methods of human resource management and training (14.7 vs. $13.7 \%)$, internal R\&D (68.8 vs. $60.2 \%)$ and especially information and software systems (42.2 vs. $28 \%$ ) and acquisition of technology, patents and licences (37.6 vs. 26.4\%).

\subsubsection{A quantitative approach}

In terms of firms' estimates of the increased investment resulting from their relationships with TIs or PROs, PROs generally have a bigger effect, although the only type of investment showing statistically significant difference in means is acquisition of technol ogy, patents and licences. The impact of TIs is higher (and statistically significant) on investments in external R\&D (Table 1).

\subsection{Intangible impact}

Intangible impact is very similar among TIs and PROs, although there are some nuances (Table 1). PROs' impact is higher on improvements to relationships among firms' R\&D and other departments (43.1 vs. $23.8 \%)^{9}$ and on the utilization of other external knowledge sources $(87.2$ vs. $78 \%)$. TIs, on the other hand, perform better in improved information on public calls (77.3 vs. $63.3 \%$ ). Other interesting, but non significant differences, are that TIs

\footnotetext{
${ }^{8}$ In the sense that we limit the influences of outliers by applying winsorization.

9 Anecdotal evidence suggest that this result might be due not so much to the actual interaction with a university, but to the greater initial distance between the R\&D and other firm departments in the case of those firms interacting with them, compared to the situation in firms that interact with TIs.
} 
Table 2 Other impacts of TIs and PROs

\begin{tabular}{lll}
\hline Other impacts & $\%$ Of firms agree with the statements \\
\cline { 2 - 3 } & TIs & PROs \\
\hline Satisfied or highly satisfied & 92 & 89.8 \\
Projects would have been developed more slowly & 48 & $63.6^{* *}$ \\
Projects would have been developed in a less ambitious way & 55.2 & 50.9 \\
Projects would have achieved worse results & 50.4 & 41.8 \\
Projects would have been developed exactly as they have been & 24.8 & 27.3 \\
Projects would not have been developed at all & 29 & 31.8 \\
\hline
\end{tabular}

$* * * p$-value $<0.01, * * p$-value $<0.05, * p$-value $<0.1$

contribute the most to the firm's ability to define and plan R\&D activities (64.3 vs. $56.9 \%$ ) and to its understanding of markets (39.8 vs. $22.1 \%)$, while PROs have a greater impact on staff learning (77.1 vs. $71.6 \%$ ), capability for team working and knowledge sharing (65.1 vs. $59.4 \%)$ and the utilization of information and software systems (35.2 vs. $28.5 \%$ ).

\subsection{Other types of impacts}

General satisfaction was slightly higher in the case of TIs (92 vs. $90 \%$ of clients in the case of PROs) (Table 2). However, PROs' clients are more likely to report that without this relationship the project would have been delayed (63.6 vs. $48 \%)$. On the other hand, TIs' clients are more likely to report that without cooperation projects would have been less ambitious (55.2 vs. $51 \%$ ) or would have produced less useful results (50.4 vs. $41.8 \%)$.

Finally, only $24.8 \%$ of TIs' clients felt that the project performance would have been much the same without collaboration with a TI. This figure is $27.3 \%$ in the case of PROs. Conversely, $31.8 \%$ of PRO clients and $29 \%$ of TI clients reported that it would have been impossible to develop the project without this external assistance.

\section{Determinants of impact: project and firm characteristics}

Although our exploratory analysis seems to suggest that the impacts of TIs and PROs differ very little (except in some very specific areas), this does not take account of the charac teristics of the clients or the features of the relationships. Some studies (Barge Gil et al. 2008) show that, at least in the Spanish case, the types of clients served by TIs and RTOs differ. The importance of relationship and firm specific factors in affecting impact has also been highlighted by studies of other situations, such as Cooperative Research and Development Agreements (Mowery 2003), the role played by Japanese Kosetsushi Centres (Izushi 2003) and the relationships between small and medium sized enterprises (SMEs) and external sources (Okamuro 2007).

Therefore, we analyse the influence of several firm and relation specific characteristics that are indicative of the impact obtained (Feller et al. 1996) and to verify whether, once other factors are taken into account, the impacts of TIs and PROs are different. ${ }^{10}$

\footnotetext{
${ }^{10} \mathrm{We}$ are aware that the proper econometric way to perform the analysis would rely on instrumental variables. However, small sample size and the absence of good instruments led us to take the 'more simple' empirical strategy based on regressions with controls (Jaffe 2002).
} 


\subsection{Definition of explanative variables}

\subsubsection{Firms' characteristics}

It is argued that smaller firms find it more difficult to benefit from external sources of knowledge (Rothwell and Dodgson 1991; Belderbos et al. 2004), leading to the paradox that those firms more in need of external knowledge are those that less frequently exploit it (Hassink 1997). It has also been argued, however, that size is not an explanatory factor per se, but is a proxy for factors, such as the existence of scale economies in knowledge production, the capability to specialize better in some functions, improved communication abilities and management techniques (Beise and Stahl 1999; Huergo 2006). This argument seems to be supported by analyses of small technology based firms (Heijs 2004), which demonstrate high absorptive capacity. We defined Size as the log of the number of the firm's employees as a proxy for the influence of size.

The concept of absorptive capacity encompasses the characteristics of firms that influence the impact of external sources of knowledge. Absorptive capacity can be defined as the ability to recognize the value of new external knowledge, assimilate it and apply it to commercial ends (Cohen and Levinthal 1990). The most frequent indicators used to proxy for absorptive capacity are related to R\&D inputs. However, some authors (Lane et al. 2006; Muscio 2007) have criticized their use, pointing out that the original concept of absorptive capacity goes beyond formal $R \& D$ activities. A related indicator could be percentage of staff with a university degree (Degree), which is what we use here.

Other approaches to assessing absorptive capacity include the existence of incoming spillovers, which are an incentive for cooperation. Firms receiving higher inward spillovers will benefit more from external knowledge sources (Cassimann and Veugelers 2002; López 2008). We operationalize this variable (Spillovers) by adding together the importance ascribed by the firm to three public sources of information (conferences, trade fairs and exhibitions; scientific journals and trade/technical publications; and professional and industry associations) and rescaling the indicator between zero and 1.

Attitudinal factors are also very important for absorptive capacity and to the success of relationships (Mole et al. 2008). More precisely, an open to the environment style of management is highlighted as an important factor (Laursen and Salter 2004). Openness to new ideas could be viewed as a form of absorptive capacity, in that it represents the cognitive capability to assimilate and act on new ideas (Fey and Birkinshaw 2005). This type of management is related to the search for partners, their identification and selection and recognition of signals relating to useful knowledge sources (Fontana et al. 2006). We proxy for this type of management with a dummy that takes the value 1 if the firm's top management is involved in a relationship with a PRO or a TI (Top M), and zero otherwise.

Finally, the domestic or foreign property of firms could influence the level of interac tion, and the impact derived by firms from their interactions with PROs or TIs. Domestic firms could benefit more based on greater familiarity (Arundel and Geuna 2004). Also, foreign affiliates might prefer to use PROs or TIs from their home countries; on the other hand, their location in a foreign country could have been chosen deliberately to be near to a particular PRO or TI with the aim of benefiting from its knowledge. We control for this effect using a dummy that takes the value 1 if the firm is foreign owned (Multi). ${ }^{11}$

$\overline{11}$ The authors are grateful to an anonymous referee for highlighting this point. 


\subsubsection{Relationship characteristics}

Several characteristics of the interactions with RTOs are likely to affect their impact.

First, the longevity of the relationship between the firm and a specific TI or PRO has been highlighted as being significant (Izushi 2003). The argument is that the continued use of the same external knowledge source favours the level of return that can be expected, promotes the establishment of routines to facilitate it, and reduces the risk of opportunistic behaviour, thus helping to build trust, (MacPherson 1997; Narula and Hagedoorn 1999; Izushi 2003; Dahl and Pedersen 2004). Age is represented as the log of the number of years since the beginning of the relationship between the firm and the specific PRO/TI (Age).

Second, the motivation to interact with a knowledge source can vary and is usually distinguished as economic or technological. Economic motivations are mainly related to cost and economic risk reduction (Veugelers 1998; Bayona et al. 2001; Miotti and Sachwald 2003; Geisler 2001; Becker and Dietz 2004; Narula 2004), but also to image and reputation building (Geisler 2001). Technological motivations are related to the search for complementarities, that is, knowledge or experience not available inside the firm, that is needed to carry out innovation activities and complements in house own knowledge and develops the learning process (Sakakibara 1997; Howells et al. 2003; Meeus et al. 2004). Other technologically related motivations include the exploration of new areas to gain information about future innovation opportunities (Narula 2001; Mol 2005). Also, the use of external sources of knowledge allows the firm to obtain more objective knowledge about its situation, compared to other organizations in its environment (O'Farrell and Hitchens 1990; Wood 2002). We develop a principal component analysis (PCA) to investigate the motives for interacting with the RTO and use the second rotated factor, which distin guishes between technological and economic motivations ( $\mathrm{T}$ Mot). The loadings are provided in the Appendix 2.

Third, the way the relationship is implemented affects its impact (Okamuro 2007). Good management will improve results. The provision of knowledge intensive service usually requires face to face interactions because, to an extent, the resulting output is co produced by provider and customer (O'Farrell and Moffat 1991; Ham and Mowery 1998; Bozeman 1999; Guilhon 2004). The intensity and type of contacts can influence the impact (Ham and Mowery 1998; Bennet and Robson 1999; Goe et al. 2000; Autio et al. 2008) and SMEs frequently report communication problems in their relationships with external sources (Ranga et al. 2008). We try to capture this effect with a dummy variable that takes the value 1 if any type of close interaction has been produced: secondment of firm staff to the PRO/TI, secondment of PRO/TI staff to the firm, or development of mixed teams (Interact).

Fourth, the type of service provided within the relationship is likely to influence the output attained (Shapira et al. 1996). The characteristics of R\&D projects differ greatly from the characteristics of training courses, technical services or consultancy activities (Izushi 2003, 2005). The requirements of trust, good communication and previous expe rience differ widely in these contexts (Bayona et al. 2001; Carrincazeaux et al. 2001; Meeus et al. 2004). However it is not clear which type of service will have a greater impact because R\&D projects, which a priori are more likely to pursue more advanced goals, are also more uncertain and difficult to implement. In addition, despite the strong focus of policy makers and managers on $\mathrm{R} \& \mathrm{D}$, non $\mathrm{R} \& \mathrm{D}$ activities are important for the achievement of innovation results (Barge Gil et al. 2008) and firms demand comprehensive service packages, that include R\&D and non R\&D activities (Preissl 2006). Also, several channels have been found to be important in university industry interactions (D'Este and Patel 2007; Perkmann and Walsh 2007) so that diversification might result in a higher 
impact. Accordingly, we used two measures: percentage of total services devoted to R\&D projects (Serv R\&D) and percentage of total services devoted to R\&D projects squared, so that the importance of the diversification of services is also analysed (Serv R\&D2).

Finally, the extent of the relationship should also be measured to control for impact. A priori, those relationships that involve higher levels of funding and more people might be supposed to have a higher impact in absolute terms. We use the logarithm of the amount of money contracted by the firm to the PRO/TI in the previous 3 years ${ }^{12}$ (Volume).

\subsection{Empirical model}

The analysis of our impact determinants is represented in the following equation:

$$
I_{i} \quad \beta_{i 0}+\beta_{i 1} \mathrm{TI}_{j}^{\prime}+\sum_{k 2}^{p} \beta_{i k}^{f \mathrm{FIRM}^{2}} \mathrm{FIRM}_{k}^{\prime}+\sum_{l p+1}^{q} \beta_{i l}^{\mathrm{REL}} \mathrm{REL}_{l}^{\prime}+\varepsilon_{i}
$$

where $I_{i}$ represents the different indicators of impact, $\beta_{i 1}$ the impact of the TI (compared with a PRO) for each indicator of impact, $\beta_{i k}^{f \text { FIRM }}$ the impact of the $k$ characteristics of firms in each type of impact, $\beta_{i l}^{\mathrm{REL}}$ the impact of the $l$ characteristics of the relationship and $\varepsilon_{i}$ the error term.

First, we estimate one equation for each type of impact (technical, economic, invest ment, intangible and other) and then estimate two additional equations using a quantitative approach to the economic and investment impacts. Different estimation techniques are employed to deal with the special features of each variable (ordered logit, robust least squares and Tobit $^{13}$ ).

\subsection{Results}

\subsubsection{Technical results}

Four types of technical impacts were considered: new or improved goods, new or improved services, new or improved processes and new logistic innovations. We build the variable Tech Impact by adding the number of technical impacts considered. The resulting variable takes a range of values from zero (no impacts achieved) to 4 (achievement of the four technical impacts considered) so that an ordered logit can be used to run the estimation.

The results (Table 3) show a statistically similar impact for TIs and PROs and highlight that the implication of the firms' top management helps to attain more varied technical impacts, as does the existence of a close interaction and diversified provision of services. That is, a higher percentage of $R \& D$ increases the technical impact, but the quadratic term is negative, showing an inverted $\mathrm{U}$ shaped influence.

\subsubsection{Economic results}

First, we apply the qualitative variables. Seven economic impacts are considered: sales, exports, production costs, profits (before tax), productivity, employment and number of

\footnotetext{
12 Unfortunately, we do not have data on total money contracted during the previous 5 years. However, we think that 3 years is a good proxy for this ideal measure.

13 In the case of quantitative impact we proved both robust least squares and Tobit. The high number of zero values made us opt for the Tobit estimations.
} 
clients. Each is rated from 1 (high positive influence) to 5 (high negative influence). We perform a PCA of these variables and use the first factor to proxy for economic results (loadings are provided in the Appendix 2).

We find that the economic impact is higher for firms with a higher percentage of qualified people, for firms with involvement from top management, and for national firms. Age of the relationship, close interaction and diversified provision of services also posi tively influence the economic impact. No statistically significant difference was found between PROs and TIs.

Second, we apply the quantitative variable. Again, the seven economic impacts were considered and the resulting variable is the mean of the percentage of influence of the TI/ PRO on each variable.

Economic quantitative impact was found to be higher among TIs when we controlled for the characteristics of the firms and the relationship. In addition, firms with a higher percentage of qualified people report a higher economic impact, and close interaction also positively influence this impact.

\subsubsection{Investments results}

First, we apply the qualitative variables. Seven types of investment are considered: Facilities and machinery, Information and software systems, New methods of human resource management and training, Internal R\&D, External R\&D, Acquisition of tech nology, patents and licences, External, non R\&D related, innovation services. We perform a PCA for these variables and use the first factor to proxy for investment results (loadings are provided in the Appendix 2).

We find that firms with more qualified staff and heavier involvement of top manage ment, report a higher impact on investments. Also, the length of the relationship, the motivation of technical objectives, and the existence of close interactions all positively affect the impact on investments. The percentage of services devoted to R\&D activities shows an inverted $U$ shape influence. On the other hand, whether the relationship is with a TI or a PRO makes no significant difference.

Second, we investigate the determinants of the quantitative impact, defining it, as in the case of economic impact, as the mean of the percentage contribution of the PRO/TI to the growth rate of firm investment in each type of investment.

Our results show that, again, the impact of TIs and PROs is not significantly different. Among the specific firm factors, the percentage of qualified staff and the involvement of top management were found to be relevant. On the other hand, the length of the rela tionship and the closeness of the interaction have a high and positive effect on quantitative impact on investment. Also, the percentage of R\&D projects over total services show an inverted $\mathrm{U}$ shape influence.

\subsubsection{Intangible impact}

A measure of intangible impact is developed by performing a PCA of the influence of PROs/TIs on eight intangible firm impacts (measured on a 15 scale, as the case of economic and investment impact): Learning and staff training in new areas, Enhanced ability to teamwork and knowledge sharing, Better market understanding, Enhanced ability to define and plan innovation activities, Better use or selection of information and software 
Table 3 Results of the multivariate regression analysis to estimate the determinants of different types of impact

\begin{tabular}{|c|c|c|c|c|c|c|c|c|}
\hline & \multicolumn{2}{|c|}{ Technical impact } & \multicolumn{2}{|c|}{$\begin{array}{l}\text { Economic impact } \\
\text { (qualitative) }\end{array}$} & \multicolumn{2}{|c|}{$\begin{array}{l}\text { Economic impact } \\
\text { (quantitative) }\end{array}$} & \multicolumn{2}{|c|}{$\begin{array}{l}\text { Investment impact } \\
\text { (qualitative) }\end{array}$} \\
\hline & Coefficient & SE & Coefficient & SE & Coefficient & SE & Coefficient & SE \\
\hline RTO & 0.2927 & 0.2915 & 0.0123 & 0.2599 & $0.0715^{*}$ & 0.0394 & 0.0601 & 0.2303 \\
\hline Size & 0.0340 & 0.1488 & 0.0511 & 0.0927 & 0.0031 & 0.0173 & 0.1312 & 0.0825 \\
\hline Degree & 0.0063 & 0.0052 & $0.0119 * *$ & 0.0041 & $0.0017 * *$ & 0.0007 & $0.0137 * * *$ & 0.0041 \\
\hline Spillovers & 1.0699 & 0.9610 & 0.6368 & 0.8665 & 0.1589 & 0.1471 & 0.3439 & 0.7787 \\
\hline Top M & 0.7310 & 0.3014 & $0.4411^{*}$ & 0.2605 & 0.0632 & 0.0475 & $0.4283^{*}$ & 0.2328 \\
\hline Multi & 0.2803 & 0.4328 & $0.8200^{*}$ & 0.4352 & 0.0697 & 0.0757 & 0.1502 & 0.4302 \\
\hline Age & 0.2151 & 0.2757 & $0.3747^{*}$ & 0.1984 & 0.0531 & 0.0343 & $0.4054 * *$ & 0.1693 \\
\hline T Mot & 0.0776 & 0.1360 & $0.2326^{* *}$ & 0.1157 & 0.0219 & 0.0199 & $0.1993 * *$ & 0.0897 \\
\hline Interact & $0.5834 * *$ & 0.2974 & $0.4364 *$ & 0.2553 & $0.0965 * *$ & 0.0409 & $0.8675^{* * * *}$ & 0.2272 \\
\hline Serv R\&D & 0.0449 & 0.0166 & $0.0326^{* *}$ & 0.0141 & 0.0024 & 0.0023 & $0.0238^{*}$ & 0.0125 \\
\hline Serv $R \& D 2$ & 0.0004 & 0.0002 & $0.0003^{* *}$ & 0.0001 & 0.0000 & 0.0000 & $0.0002 * *$ & 0.0001 \\
\hline Volume & 0.0955 & 0.0728 & 0.0107 & 0.0595 & 0.0108 & 0.0108 & 0.0099 & 0.0619 \\
\hline Constant & & & 1.6624 & 0.8594 & 0.0227 & 0.1429 & $2.6706^{* * * *}$ & 0.9109 \\
\hline Method & $\begin{array}{c}\text { Ordered } \\
\text { logit }\end{array}$ & & RLS & & Tobit & & RLS & \\
\hline \multirow[t]{3}{*}{$\begin{array}{l}\text { Significance } \\
\text { Test }\end{array}$} & \multicolumn{2}{|l|}{$\begin{array}{l}\text { Prob > chi2 } \\
\quad=0.0000\end{array}$} & \multicolumn{2}{|l|}{$\begin{array}{l}\text { Prob }>F \\
\quad=0.0000\end{array}$} & $\begin{array}{l}\text { Prob }>F \\
\quad=0.0034\end{array}$ & \multicolumn{3}{|c|}{$\begin{array}{l}\text { Prob }>F \\
\quad=0.0000\end{array}$} \\
\hline & \multicolumn{5}{|c|}{ Investment impact (quantitative) Intangible impact } & \multicolumn{3}{|c|}{ Other impacts } \\
\hline & Coefficient & \multicolumn{2}{|c|}{ SE } & Coefficient & SE & \multicolumn{2}{|c|}{ Coefficient } & SE \\
\hline RTO & 0.0178 & \multicolumn{2}{|c|}{0.0370} & 0.1670 & 0.2412 & \multicolumn{2}{|c|}{0.2530} & 0.3286 \\
\hline Size & 0.0044 & \multicolumn{2}{|c|}{0.0171} & 0.0229 & 0.1006 & \multicolumn{2}{|c|}{0.0812} & 0.1243 \\
\hline Degree & $0.0012 *$ & \multicolumn{2}{|c|}{0.0007} & $0.0084^{*}$ & 0.0050 & \multicolumn{2}{|c|}{0.0014} & 0.0058 \\
\hline Spillovers & $0.1756 * *$ & \multicolumn{2}{|c|}{0.1207} & 0.3733 & 0.9803 & \multicolumn{2}{|c|}{1.4826} & 1.2734 \\
\hline Top M & $0.0846 * *$ & \multicolumn{2}{|c|}{0.0399} & $0.4640 *$ & 0.2459 & & .4011 & 0.3453 \\
\hline Multi & 0.0667 & & 683 & 3235 & 0.4020 & & .2743 & 0.5094 \\
\hline Age & 0.0725 & & 296 & $4781 * *$ & 0.1857 & & $.4620 *$ & 0.2716 \\
\hline T Mot & 0.0050 & & 149 & .1456 & 0.1012 & & $.5801 * * *$ & 0.1362 \\
\hline Interact & $0.0967 * * *$ & & 356 & $.8837 * * *$ & 0.2348 & & $.0059 * * *$ & 0.3172 \\
\hline Serv $R \& D$ & $0.0044 * *$ & & 020 & .0147 & 0.0139 & & .0065 & 0.0161 \\
\hline Serv $R \& D 2$ & $0.0000 * *$ & & 000 & .0002 & 0.0001 & & .0000 & 0.0002 \\
\hline Volume & 0.0063 & & 097 & .0056 & 0.0649 & & .0414 & 0.0838 \\
\hline Constant & 0.0543 & & 372 & .7449 ** & 0.8549 & & & \\
\hline Method & Tobit & & RL & & & Ord & dered logit & \\
\hline Significance $t$ & $\begin{array}{l}\text { Prob }> \\
\quad F=0.0000\end{array}$ & & & $\begin{array}{l}b> \\
F=0.0000\end{array}$ & & & $\begin{array}{l}\mathrm{b}>> \\
\mathrm{chi} 2=0.0002\end{array}$ & \\
\hline
\end{tabular}

*** $p$-value $<0.01, * * p$-value $<0.05, * p$-value $<0.1$

systems, Improved relationships between firm's R\&D and other departments, Improved utilization of other knowledge external sources and Better information on public innova tion programmes. Loadings are provided in the Appendix 2. 
The results show that firms with more qualified staff and top management involvement achieve a higher impact. Also, the age of the relationship and the closeness of the inter action positively affect the degree of intangible impact. Again, the impacts of TIs and PROs are not different from a statistically point of view.

\subsubsection{Other impacts}

We use the general level of the satisfaction from 1 (very unsatisfied) to 5 (very satisfied) to obtain a general measure of the impact of the relationship. We rescaled it from 0 to 4 and perform an ordered logit regression.

The results show that the general level of satisfaction is not significantly different between TIs and PROs. In addition, although the characteristics of firms do not affect their general satisfaction, the characteristics of the relationships do. The length of the rela tionship, technological motives and close interaction positively affect the general satis faction of customers.

\subsection{Summary and discussion of results}

Several interesting issues emerge from our results. First, controlling by the characteristics of firms and specific relationships, we find that TIs have more economic impact than PROs, from our rough quantitative perspective. However, for the other impacts the differences between organizations are not significant.

Second, we find that the percentage of staff with a university degree adds to economic impact and enables a greater impact on investments and on intangibles, and that attitude is very important for explaining all types of impact, and also the general degree of satis faction. We find that size and spillovers are not relevant in explaining any type of impact and that headquarters location matters only for economic impact. We would argue that the effect of size is related more to the likelihood of cooperation, because of the existence of certain barriers which small firms find it more difficult to overcome (Barge Gil 2009). We could perhaps apply this argument to the importance of spillovers although the evidence for this variable is scant and more analyses are required. The effect of foreign affiliation could be related to the concentration of $R \& D$ activities in the host country.

Third, the characteristics of the relationship are very important: owing to lack of data these have not been considered in many of the existing studies. More precisely, close interaction between the knowledge provider and the customer results in a higher impact, of whatever type. The length of the relationship, which has been highlighted as a very relevant factor, positively influences the impact on investments, the intangible impact and the general satisfaction of the firm. That is, the technical, more immediate and the eco nomic impact are not affected by the length of the relationship. However, the more intangible and long term impacts are affected by the process of trust building over time.

Technical (as opposed to economic) motivations affect the economic impact, the impact on investments and the general satisfaction. These results, which to an extent could seem counterintuitive, can be explained by difference between expectations and results. Some firms forge relationships with TIs or PROs to get more public funding or in the belief that it will save them some money. These firms are more likely to benefit less from the rela tionships than firms that approach TIs or PROs in the search for specific knowledge to develop projects or to explore the knowledge available in these partner organizations.

The R\&D intensity of the relationship shows an inverted $U$ shape effect for several types of impacts (technical, economic and investments). This result points to the 
importance of providing R\&D services, but also of the importance of complementarities between $R \& D$ and other activities which improve the quality of the service to firms and facilitate exploitation of the benefits of this service. Finally, and surprisingly, the amount of money invested in the services provided has no effect on the impact. More research is needed to understand this result more fully.

\section{Policy implications}

RTOs are key agents in innovation policy. The overwhelming importance of evaluating the outcome of public initiatives is now thoroughly recognized (Roessner 2002). The present study is a first step in evaluating the impact of these organizations on the private sector. Although, evaluation is generally used to justify programmes, it is also important for improving the design of programmes to better meet agents' needs (Mowery 1999).

Our first result is that firms are able to recognize the impacts of their relationships with RTOs and also are able to assess the dimensions of this impact. Intangible impacts are the most valued and apply to most firms. Firms are also able to identify different economic impacts, with improvements to sales being the most frequent and improvements in employment being less important, and the different impacts on investment, with internal and external R\&D being the most frequent and new methods of human resource man agement and training the least. Thus, actually asking users about the effects of these relationships would provide interesting and useful information which could be comple mented with other methodologies.

The second result is that differences in the impacts of relationships with PROs and TIs are not very pronounced. This result, combined with empirical evidence that these orga nizations usually target different types of firms (Barge Gil et al. 2008), points to their complementarity from a policy point of view.

Third, the importance of qualified workers and an open attitude reflects the importance of firms' internal capabilities (understood as including both knowledge and management) to benefit from external knowledge. This is indicative that policy should try to foster the internal capabilities of firms. More precisely, it suggests that there is a relationship between innovation policy and education and labour policy. The transfer of students to firms and the configuration of open attitudes are important indirect factors facilitating technology transfer.

A fourth and very important result is related to the length of a relationship, which, in turn is related to the importance of trust between the partners for achieving a higher impact. This aspect is highlighted in other studies (Izushi 2003, Modrego Rico et al. 2005) and its implications are twofold. First, RTOs should be given public support in their first years of existence: since their impact in these years will be lower, they will find it more difficult to raise funds from the private sector. Second, public initiatives should be relatively longterm and stable: often, new RTOs are created and then disbanded after only a few years of operation, usually due to changes in the political cycle.

Finally, diversification of services influences the impact achieved. This results contrasts with the R\&D focus of many policy initiatives (Barge Gil and Modrego Rico 2008). However, some studies point to the importance of non R\&D activities (Santamaría et al. 2009). In fact, a frequent complaint from firms interacting with RTOs is that projects are too focused on R\&D at the expense of the implementation and commercialization phases. These comments have led some authors to highlight the importance of offering 
technoeconomic capabilities (Rolfo and Calabrese 2003; Barge Gil et al. 2008) instead of providing firms with technoscientific capabilities exclusively.

\section{Concluding remarks}

We developed a framework to evaluate the impact of firms' links with RTOs. We devised strategies to deal with each of the methodological problems highlighted in the literature. This allowed us to compare different types of impacts between TIs and PROs by devel oping a multidimensional approach to these impacts and exploring the factors that might influence each type of impact. We employed a new strategy to obtain some (rough) quantitative measures of economic impact and impact on investment.

This novel framework has been shown to be very useful and provides some interesting results. We observe that satisfaction with TIs and PROs services is generally very high and that firms are able to recognize the influence of these relationships in terms of various technical, economic, investment and intangible impacts.

To investigate the influence of TIs and PROs on the different types of impacts, a multivariate model is needed. Some authors have suggested that both firm factors and also those specific to the relationship might provide explanations for the impact obtained (Okamuro 2007; Mole et al. 2008). Our results support this view.

While firms' characteristics related to absorptive capacity are important, both from a knowledge and an attitudinal point of view, other factors, such as size and the importance of spillovers, are not relevant when the characteristics of the relationships are taken into account. Among these, length of the relationship, existence of close interactions, moti vations related to knowledge and receptivity to a variety of services are very important explanations of several types of impacts.

As pointed out by some authors (Martin 2003; Arnold 2004) evaluation is evolutionary and any and all evaluation will be highly imperfect; thus, the results of project evaluation should be treated with appropriate caution. There are some clear limitations to our study. First, the sample is rather small. The main problem here is that the effort involved in constructing a large sample is costly in time and money and firms are over burdened with requests for information. Perhaps one solution would be to include estimation of impact in official surveys based on a particular periodicity. Second, more information is needed on firms' characteristics. Again, some matching with official surveys would be interesting. Third, if these two limitations can be overcome, a Heckman model could be developed to take account of firms' selection of their RTO partner, thereby improving treatment of the control group. Fourth, the characteristics of TIs and PROs probably also have an effect on impact; thus, being able to match our database with other data on PRO and TI charac teristics would be of great interest.

These limitations should be priority areas for future research. And despite them, the evaluation process described and the results obtained should be of great help to policy makers designing initiatives and for stakeholders willing to evaluate them but also for TIs, PROs and firm managers who want to improve interactions with actual and potential clients.

Acknowledgments The authors acknowledge the financial support of FEDIT and the help provided by the Spanish Institute of Statistics. They also thank participants in DRUID 2009 Summer Conference for the comments received and Ángela Vásquez-Urriago for excellent research assistance. The usual disclaimer applies. 


\section{Appendix 1: Survey questionnaire (impacts)}

\section{Results of the relationship with $\mathrm{E}^{*}$ in last 5 years}

As a consequence of the relationship with $\mathrm{E}^{\star}$ during last 5 years, has your enterprise achieved any of the following?

\begin{tabular}{|l|l|}
\hline Technical results & Yes \\
\hline New or improved goods & \\
\hline New or improved services & \\
\hline New or improved production methods & \\
\hline mprovements in logistics & \\
\hline Patents
\end{tabular}

Please indicate about the contribution of $E^{*}$ to the following indicators for your firm

\begin{tabular}{|c|c|c|c|c|c|}
\hline Indicators & $\begin{array}{l}\text { Very } \\
\text { positive }\end{array}$ & Positive & Null & Negative & $\begin{array}{l}\text { Very } \\
\text { negative }\end{array}$ \\
\hline Sales & 1 & $\Gamma$ & I & $\Gamma$ & \\
\hline Exports & I & I & & I & \\
\hline Production costs & 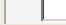 & $\Gamma$ & & 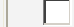 & Г \\
\hline Profits (before taxes) & I & Г & & 厂 & 1 \\
\hline Productivity & Ф & Г & & 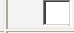 & | \\
\hline Employment & D & $\Gamma$ & I & Г & 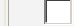 \\
\hline Number of clients & 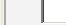 & 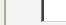 & & 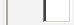 & \\
\hline
\end{tabular}

Indicate the approximate annual average variation in the following indicators, for your firm, during the last 5 years please, estimate what the annual average would have been in the case that your firm HAD NOT COLLABORATED with E* NOR CONTRACTED ITS SERVICES

\begin{tabular}{|l|l|l|}
\hline Indicators & $\begin{array}{l}\text { Annual average variation during } \\
\text { last 5 years }\end{array}$ & $\begin{array}{l}\text { Annual average variation during the last 5 years if no } \\
\text { relationship with E* had existed. }\end{array}$ \\
\hline Sales & & \\
\hline Exports & \\
\hline Production costs & \\
\hline $\begin{array}{l}\text { Profits (before } \\
\text { taxes) }\end{array}$ & \\
\hline Productivity & \\
\hline Employment & \\
\hline Number of clients & \\
\hline
\end{tabular}


Indicate your estimation of the contribution of $E^{\star}$ to the following firm investments

\begin{tabular}{|l|}
\hline Investments \\
\hline Facilities and machinery
\end{tabular}

Indicate the approximate annual average variation in the following investments of your firm during the last 5 years please, estimate what the annual average would have been in the case that your firm HAD NOT COLLABORATED with E* NOR CONTRACTED ITS SERVICES

\begin{tabular}{|c|c|c|}
\hline Investments & $\begin{array}{l}\text { Annual average of variation } \\
\text { during last } 5 \text { years }\end{array}$ & $\begin{array}{l}\text { Annual average of variation during last } 5 \text { years if } \\
\text { no relationship with } E^{*} \text { had existed. }\end{array}$ \\
\hline Facilities and machinery & & \\
\hline Information and software systems & & \\
\hline $\begin{array}{l}\text { New methods of human resource } \\
\text { management and training }\end{array}$ & & \\
\hline Internal R\&D & & \\
\hline External R\&D & & \\
\hline $\begin{array}{l}\text { Acquisition of technology. patents } \\
\text { and licenses }\end{array}$ & & \\
\hline $\begin{array}{l}\text { External non-R\&D related. } \\
\text { innovation services }\end{array}$ & & \\
\hline
\end{tabular}

Please indicate your opinion of the contribution of $E^{*}$ to the following intangible impacts in your firm

\begin{tabular}{|l|l|}
\hline Intangible impacts & Sery \\
\hline Learning and staff training in new areas
\end{tabular}

Give a general evaluation of your firm's level of satisfaction with the relationship with $E^{\star}$ over the last 5 years $(1=$ very dissatisfied, $2=$ quite satisfied, $3=$ satisfied, $4=$ very satisfied)

Indicate your agreement/disagreement with the following

\begin{tabular}{|l|}
\hline Projects would have been developed more slowly \\
\hline Projects would have been developed in a less ambitious way \\
\hline Projects would have achieved worse results \\
\hline Projects would have been developed in exactly the same way \\
\hline Projects would not have been developed
\end{tabular}




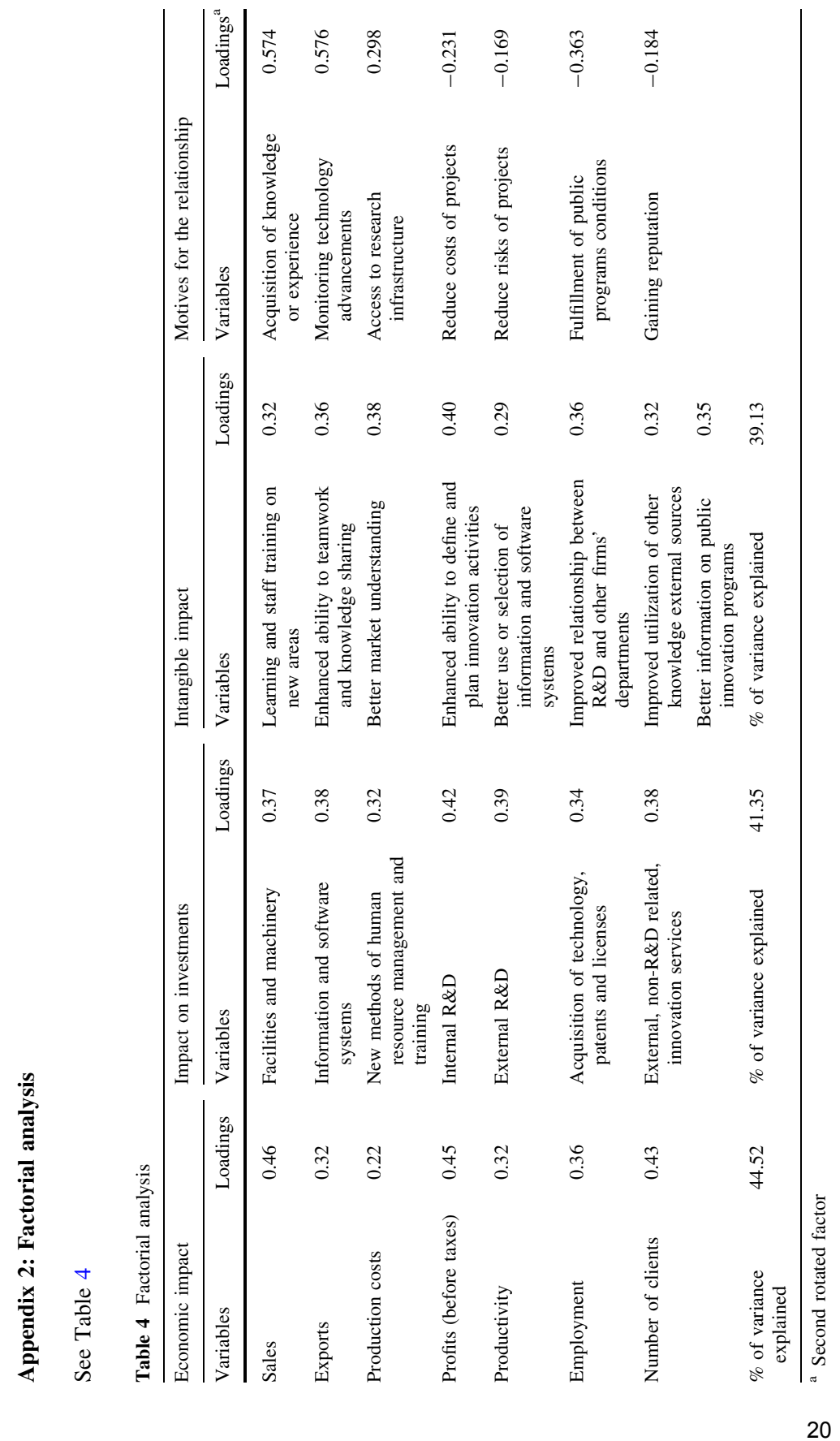




\section{References}

Amara, N., \& Landry, R. (2005). Sources of information as determinants of novelty of innovation in manufacturing firms. Evidence from the 1999 statistics Canada innovation survey. Technovation, 25, $245-259$.

Arnold, E. (2004). Evaluating research and innovation policy: A systems world needs systems evaluations. Research Evaluation, 131, 3-17.

Arora, A., Fosfuri, A., \& Gambardella, A. (2001). Markets for technology. The economics of innovation and corporate strategy. Cambridge, MA: The MIT Press.

Arundel, A., \& Geuna, A. (2004). Proximity and the use of public science by innovative European firms. Economics of Innovation and New Technology, 13(6), 559-580.

Autio, E., Kanninen, S., \& Gustafsson, R. (2008). First- and second-order additionality and learning outcomes in collaborative R\&D programs. Research Policy, 37, 59-76.

Barge-Gil, A. (2009). Cooperation-based innovators and peripheral cooperators: An empirical analysis of their characteristics and behaviour. Paper presented at DRUID Conference, June, in Copenhaguen, Denmark. http://www2.druid.dk/conferences/viewabstract.php?id=5659\&cf=32. Accessed May 18, 2009.

Barge-Gil, A., \& Modrego-Rico, A. (2008). Are technology institutes a satisfactory tool for public intervention in the area of technology? A neoclassical and evolutionary evaluation. Environment and Planning C: Government and Policy, 26(4), 808-823.

Barge-Gil, A., Santamaría, L., \& Modrego, A. (2008). Complementarities between universities and technology institutes. New lessons and perspectives. Paper presented at DRUID Conference, June, in Copenhaguen, Denmark. http://www2.druid.dk/conferences/viewpaper.php?id=3352\&cf=29. Accessed May 16, 2008.

Bayona, C., García-Marco, T., \& Huerta, E. (2001). Firms motivations for cooperative R\&D: An empirical analysis of Spanish firms. Research Policy, 30, 1289-1307.

Becker, W., \& Dietz, J. (2004). R\&D cooperation and innovation activities of firms-evidence for the German manufacturing industry. Research Policy, 33, 209-223.

Beise, M., \& Stahl, H. (1999). Public research and industrial innovations in Germany. Research Policy, 28, $397-422$.

Belderbos, R., Carree, M., Diederen, B., Lokshin, B., \& Veugelers, R. (2004). Heterogeneity in R\&D cooperation strategies. International Journal of Industrial Organisation, 22, 1237-1263.

Bennet, R., \& Robson, P. (1999). Intensity of interaction in supply of business advice and client impact: A comparison of consultancy, business associations and government support initiatives for SMEs. British Journal of Management, 10, 351-369.

Boekholt, P., Lankhuizen, M., Arnold, E., Clarke, J., Kuusisto, J., de Laat, B., et al. (2001). An international review of methods to measure relative effectiveness of technology policy instruments. Final Report. Technopolis. http://www.technopolis-group.com/resources/downloads/reports/261 EZ Final 010723. pdf. Accessed 21 November 2007.

Bozeman, B. (1999). Commercialization of federal laboratory technology. Results of a study of industry partners. In R. P. Oakey (Ed.), New technology-based firms in the 1990s (Vol. 3, pp. 127-139). London: Paul Chapman Publishing.

Bozeman, B. (2000). Technology transfer and public policy: A review of research and theory. Research Policy, 29, 627-655.

Brown, M. A., Berry, L. G., \& Goel, R. K. (1991). Guidelines for successfully transferring government sponsored innovations. Research Policy, 20, 121-143.

Buisseret, T., Cameron, H., \& Georghiu, L. (1995). What difference does it make? Additionality in the public support of R\&D in large firms. International Journal of Technology Management, 104-6, 587-600.

Carrincazeaux, C., Lung, Y., \& Rallet, A. (2001). Proximity and localisation of corporate R\&D activities. Research Policy, 30, 777-789.

Cassimann, B., \& Veugelers, R. (2002). R\&D cooperation and spillovers. Some empirical evidence from Belgium. American Economic Review, 92(4), 1169-1184.

Cohen, W., \& Levinthal, D. (1990). Absorptive capacity: A new perspective on learning and innovation. Administrative Science Quarterly, 35(1), 128-152.

Cozzarin, B. (2008). Data and the measurement of R\&D program impacts. Evaluation and Program Planning, 31, 284-298.

D'Este, P., \& Patel, P. (2007). University-industry linkages in the UK: What are the factors underlying the variety of interactions with industry? Research Policy, 36, 1295-1313.

Dahl, M. S., \& Pedersen, C. (2004). Knowledge flows through informal contacts in industrial clusters: Myth or reality? Research Policy, 33, 1673-1686. 
Feller, I., Glasmeier, A., \& Mark, M. (1996). Issues and perspectives on evaluating manufacturing modernization programs. Research Policy, 25, 309-319.

Fey, C., \& Birkinshaw, J. (2005). External source of knowledge: Governance mode, and R\&D performance. Journal of Management, 314, 597-621.

Fontana, R., Geuna, A., \& Matt, M. (2006). Factors affecting university-industry R\&D projects: The importance of searching, screening and signalling. Research Policy, 35, 309-323.

Fromhold-Eisebith, M., \& Schartinger, D. (2002). Universities as agents in regional innovation systems. Evaluating patterns of knowledge intensive collaboration in Austria. In Z. Acs, H. de Groot, \& P. Nijkamp (Eds.), The emergence of the knowledge economy (pp. 173-194). New York: Springer.

Gallouj, C. (1997). Asymmetry of information and the service relationship: Selection and evaluation of the service provider. International Journal of Service Industry Management, 8(1), 42-64.

Geisler, E. (2001). Explaining the generation and performance of intersector technology cooperation. A survey of the literature. Technology Analysis \& Strategic Management, 13(2), 195-206.

Goe, W., Lentnek, B., MacPherson, A., \& Phillips, D. (2000). The role of contacts requirement in producer service location. Environment and Planning A, 32, 131-145.

Guilhon, B. (2004). Markets for knowledge: Problems, scope, and economic implications. Economics of Innovation and New Technnology, 132, 165-181.

Hagedoorn, J. (2002). Inter-firm partnerships: An overview of major trends and patterns since 1960. Research Policy, 31, 477-492.

Ham, R. M., \& Mowery, D. (1998). Improving the effectiveness of public-private R\&D collaborations: Case studies at a US weapons laboratory. Research Policy, 26, 661-675.

Hassink, R. (1997). Technology transfer infrastructures: Some lessons from experiences in Europe, the US and Japan. European Planning Studies, 5(3), 351-370.

Heijs, J. (2004). Efectividad de las políticas de innovación en el fomento de la cooperación. Economía Industrial, 346, 97-114.

Howells, J., James, A., \& Malik, K. (2003). The sourcing of technological knowledge: Distributed innovation processes and dynamic change. $R \& D$ Management, 33(4), 395-409.

Huergo, E. (2006). The role of technological management as a source of innovation: Evidence from Spanish manufacturing firms. Research Policy, 35, 1377-1388.

Izushi, H. (2003). Impact of the length of relationships upon the use of research institutes by SMEs. Research Policy, 32, 771-788.

Izushi, H. (2005). Creation of relational assets through the 'library of equipment' model: An industrial modernization approach of Japan's local technology centres. Entrepreneurship \& Regional Development, 173, 183-204.

Jaffe, A. (2002). Building programme evaluation into the design of public research-support programmes. Oxford Review of Economic Policy, 18(1), 22-34.

Lambrecht, J., \& Pirnay, F. (2005). An evaluation of public support measures for private external consultancies to SMEs in the Walloon Region of Belgium. Entrepreneurship and Regional Development, 17, 89-108.

Lane, P., Koka, B., \& Pathak, S. (2006). The reification of absorptive capacity: A critical review and rejuvenation of the construct. Academy of Management Review, 31(4), 833-863.

Laursen, K., \& Salter, A. (2004). Searching high and low: What types of firms use universities as a source of innovation? Research Policy, 33, 1201-1215.

López, A. (2008). Determinants for R\&D cooperation. Evidence from Spanish manufacturing firms. International Journal of Industrial Organisation, 26(1), 113-136.

Luukkonen, T. (2000). Additionality of EU framework programmes. Research Policy, 29, 711-724.

MacPherson, A. (1997). The role of producer service outsourcing in the innovation performance of New York state manufacturing firms. Annals of the Association of American Geographers, 871, 52-71.

Martin, S. (2003). The evaluation of strategic research partnerships. Technology Analysis \& Strategic Management, 152, 159-176.

Meeus, M., Oerlemans, L., \& Hage, J. (2004). Industry-public knowledge infrastructure interactions: Intraand inter-organizational explanations of interactive learning. Industry and Innovation, 114, 327-352.

Miotti, L., \& Sachwald, F. (2003). Co-operative R\&D: Why and with whom? An integrated framework of analysis. Research Policy, 32, 1481-1499.

Modrego-Rico, A., Barge-Gil, A., \& Núnez-Sánchez, R. (2005). Developing indicators to measure technology institutes' performance. Research Evaluation, 14(2), 177-184.

Mol, M. (2005). Does being R\&D intensive still discourage outsourcing? Research Policy, 34, 571-582.

Mole, K., Hart, M., Roper, S., \& Saal, D. (2008). Differential gains from business link support and advice a treatment effects approach. Environment and Planning C: Government and Policy, 26, 315-334.

Mowery, D. (1999). Collaborative R\&D. How effective is it? Issues in Science and Technology, Fall, 3, 7-44. 
Mowery, D. (2003). Using cooperative research and development agreements as S\&T indicators: What do we have and what would we like? Technology Analysis \& Strategic Management, 152, 189-205.

Muscio, A. (2007). The impact of absorptive capacity on SMEs' collaboration. Economics of Innovation and New Technology, 16(8), 653-668.

Narula, R. (2001). Choosing between internal and non-internal R\&D activities: Some technological and economic factors. Technology Analysis \& Strategic Management, 133, 365-387.

Narula, R. (2004). R\&D collaboration by SMEs: new opportunities and limitations in the face of globalisation. Technovation, 24, 153-161.

Narula, R., \& Hagedoorn, J. (1999). Innovating through strategic alliances: Moving towards international partnerships and contractual agreements. Technovation, 19, 283-294.

O'Farrell, P., \& Hitchens, D. (1990). Research policy and review 32. Producer services and regional development: A review of some major conceptual policy and research issues. Environment and Planning A, 22, 1141-1154.

O'Farrell, P., \& Moffat, L. (1991). An interaction model of business service production and consumption. British Journal of Management, 2, 205-221.

O'Farrell, P., \& Moffat, L. (1995). Business services and their impact upon client performance. An exploratory interregional analysis. Regional Studies, 292, 111-124.

Okamuro, H. (2007). Determinants of successful R\&D cooperation in Japanese small business: The impact of organizational and contractual characteristics. Research Policy, 36, 1529-1544.

Perkmann, M., \& Walsh, K. (2007). University-industry relationships and open innovation. International Journal of Management Reviews, 9(4), 259-280.

Pietrobelli, C., \& Rabellotti, R. (2007). Business Development centres in Italy: Close to firms, far from innovation. World Review of Science, Technology and Sustainable Development, 41, 38-55.

Preissl, B. (2006). Research and Technology Organizations in the service economy. Innovation, 19(1), 131-145.

Ranga, L. M., Miedema, J., \& Jorna, R. (2008). Enhancing the innovative capacity of small firms through the triple helix interactions: Challenges and opportunities. Technology Analysis \& Strategic Management, 206, 697-716.

Revilla, E., Sarkis, J., \& Modrego, A. (2003). Evaluating performance of public-private research collaborations. A DEA analysis. Journal of the Operational Research Society, 54, 165-174.

Roessner, D. (2002). Outcome measurement in the USA: State of the art. Research Evaluation, 11(2), 85-93.

Rolfo, S., \& Calabrese, G. (2003). Traditional SMEs and innovation: The role of the industrial policy in Italy. Entrepreneurship \& Regional Development, 15(3), 253-271.

Rothwell, R., \& Dodgson, M. (1991). External linkages and innovation in small and medium- sized enterprises. $R \& D$ Management, 21, 125-137.

Sakakibara, M. (1997). Heterogeneity of firm capabilities and cooperative research and development: An empirical examination of motives. Strategic Management Journal, 18, 143-164.

Santamaría, L., Barge-Gil, A., \& Nieto, M. J. (2009). Is there innovation beyond R\&D? The role played by other innovation activities. Universia Business Review, 22, 102-117.

Shapira, P., \& Youtie, J. (1998). Evaluating industrial modernization: Methods, results and insights from the Georgia manufacturing extension alliance. Journal of Technology Transfer, 23(1), 17-27.

Shapira, P., Youtie, J., \& Roessner, J. D. (1996). Current practices in the evaluation of US industrial modernization programs. Research Policy, 25, 185-214.

van Helleputte, J., \& Reid, A. (2004). Tackling the paradox: Can attaining global research excellence can be compatible with local technology development? R\&D Management, 341, 33-44.

Veugelers, R. (1998). Collaboration in R\&D. An assessment of theoretical and empirical findings. The Economist, 149, 419-443.

Williams, D., \& Rank, D. (1998). Measuring the economic benefits of research and development: The current state of the art. Research Evaluation, 71, 17-30.

Wren, C., \& Storey, D. (2002). Evaluating the effect of soft business support upon small firm performance. Oxford Economic Papers, 54, 334-365.

Wood, P. (2002). Knowledge-intensive services and urban innovativeness. Urban Studies, 39(5-6), 993-1002.

Youtie, J., Bozeman, B., \& Shapira, P. (1999). Using an evaluability assessment to select methods for evaluating state technology development programs: The case of the Georgia Research Alliance. Evaluation and Program Planning, 22, 55-64. 